\title{
Enfermedades pandémicas traídas del espacio exterior: una polémica cometaria del siglo XVII al XXI
}

\section{The pandemic diseases bring from the Space: the continuity of a cometary polemic from the XVII ${ }^{\text {th }}$ century to the XXI ${ }^{\text {st }}$}

\author{
Marcos Cortés Guadarrama \\ Universidad Veracruzana, México
}

ORCID: 0000-0002-0363-7539 marcocortes@uv.mx

\begin{abstract}
RESUMEN
En el presente artículo, se analiza la propuesta del astrofísico Chandra Wickramasinghe para explicar el origen de la Covid-19. Su teoría -tildada de pseudociencia- se debe a una tradición de la disputa cometaria, que considera un origen extraterrestre para ciertas enfermedades pandémicas. Para comprobar este hecho, se revisa lo propuesto por el médico Joseph de Escobar Salmerón y Castro en su Discurso cometológico y relación del nuevo cometa (1681). Desde la historiografía literaria, se pretende establecer que ciertos relatos, que fueron establecidos por comunidades instruidas del barroco novohispano para explicar las enfermedades de su tiempo -englobadas bajo el concepto de peste y sus síntomas-, se han transfigurado en la actual pandemia de siglo xxi, vivida desde México. Se concluye que, con importantes matices y diferencias, además de ciencia, hay una tradición literaria que se argumenta en ambas teorías, incluso cuando median casi trescientos cincuenta años entre sus respectivas circunstancias y realidades.
\end{abstract}


Palabras clave: Joseph de Escobar Salmerón y Castro; medicina novohispana; cometas; Chandra Wickramasinghe; literatura y ciencia.

\section{Abstract}

The approach of the astrophysicist Chandra Wickramasinghe, which explains the origin of the COVID-19, is analyzed in the present article. His theory -branded as pseudoscience- results from the tradition on the topic comet/asteroid, which declares an alien origin for certain pandemic diseases. To show this fact, the theory of the physician Joseph de Escobar Salmerón y Castro is scrutinized in his Discurso cometológico y relación del nuevo cometa (1681). Based on the literary historiography, the intention is to state that certain stories provided for baroque literate communities from the New Spain explain the diseases of their time - known under the name of plague and its symptom- and have transfigured in the actual plague of COVID-19. It is concluded, with important nuances and differences, that in addition to a modern Science, there is a literary tradition which can be read in both theories, even though there is a difference of almost three hundred and fifty years between them and their respective statements.

Keywords: Joseph de Escobar Salmerón y Castro; medicine from New Spain; comets; Chandra Wickramasinghe; literature \& science.

\section{INTRODUCCIÓN}

La noticia de que la actual pandemia tuvo su origen en un cometa rápidamente abandonó las publicaciones de investigación especializadas en cosmología. Como era de esperarse, los diarios han jugado un papel importante en la divulgación de teorías e historias globales o locales relacionadas con el origen y documentación sobre la pandemia provocada por el nuevo coronavirus: SARS-COV-2, hecho que se aúna a un factor conocido: las redes sociales también han formado parte de esta divulgación. Sin embargo, este ha sido uno de los espacios idóneos para la divulgación de noticias falsas, mismas que alientan tal nivel de desinformación que, en ciertos países, se ha tenido que legislar para prohibir esta injerencia. En 
este sentido, no debe pasarse por alto que la noticia que a continuación se revisa también fue compartida en redes sociales.

Para el caso del orbe hispánico, el 19 de marzo de 2020 el diario español $A B C$ difundió la traducción de una noticia que se oponía al resto de las especulaciones que se barajaban como posibles orígenes de la pandemia, con el título "El coronavirus llegó del espacio: la disparatada teoría de un famoso astrofísico". Entre otras cosas, se comentaba que, junto a murciélagos en venta para su consumo en el mercado de Wuhan y laboratorios secretos en la misma ciudad, Chandra Wickramasinghe, astrofísico de renombre, proponía otro origen: como un partidario de la teoría de la pansmermia, ${ }^{1}$ abiertamente declara que -entre varias cuestiones y sus maticeslos cometas o asteroides transportan bacterias u otros microorganismos, es decir, vida. Con base en esta teoría, Wickramasinghe señala que este sería uno de los posibles orígenes del nuevo virus. La traducción citaba que, días antes, el científico británico, de origen cingalés, comentó:

que era posible que el virus estuviera viviendo en un cometa y que una parte de esta roca con este patógeno habría caído en forma de bola de fuego en China en octubre de 2019. [La noticia se acompaña de una imagen de la supuesta bola de fuego que se vio en los cielos chinos en esa fecha]. Señaló además que era probable que otros cuerpos [cometas, asteroides] hayan portado virus, cruzando su trayectoria con la nuestra y haber comenzado brotes de otras enfermedades, tales como el síndrome respiratorio agudo grave (Exclusivo Premium, 2020, párr. 3) (SRAs).

La nota proseguía con un subtítulo: “¿Qué hay de verdad?” Ahí se cuestionaba tal teoría, sostenida por el científico desde hace más de cuarenta años: "La comunidad científica lleva años echando abajo

${ }^{1}$ El mismo artículo explica, al final, que la panspermia nació en el siglo XIx y afirma que la vida en la tierra se creó por vida venida del espacio exterior-microorganismos, material biológico. Y se señala que no hay pruebas de ello: "La hipótesis afirma que los materiales podrían sobrevivir en una roca espacial, en una especie de letargo y protegidos de la radiación en el interior de meteoritos y cometas hasta llegar a la Tierra y emerger." 
los argumentos de Wickramasinghe sobre que cualquier enfermedad de este tipo podría tener orígenes extraterrestres" (párr. 4). E incluso, oponiendo la opinión de otra "autoridad" en la divulgación de la ciencia, Graham Lau, ${ }^{2}$ se citaba el negativo concepto de "pseudociencia" contra Wickramasinghe y otros que no pueden probar su teoría. En su defensa, se apuntaba que "Se han encontrado moléculas orgánicas, como aminoácidos, en el interior de rocas recuperadas de pasados impactos". No obstante, no hay prueba contundente de lo que afirma el astrofísico. Con ello, termina el artículo del diario $A B C$.

No es de mi interés decantarme por una demostración de la validez o supresión de la teoría de Wickramasinghe, pues no cuento con una formación científica para ello. Sin embargo, desde mi campo de trabajo, la filología, me interesa concentrarme en el relato, en la narración que alude la postura de este científico. Y es que, en cierto sentido, lo que destaca y suprime con su teoría responde a una tradición literaria que se prolonga hasta la conceptualización aristotélica-ptolemaica del cielo ${ }^{3}$ y el desarrollo medieval del supuesto influjo nefasto que sobre la tierra y los humanos anunciaban los cometas. De hecho, hace más de once años que el propio Wickramasinghe es consciente de esta tradición del pensamiento en torno a los cometas. En aquel otro trabajo, demostró gran nivel de documentación al referir y proponer que la gran plaga de Atenas, ocurrida en el año 430 A. C., es uno de los mejores casos para ilustrar el origen de una enfermedad provocada por un cometa, al igual que la peste negra, en la Baja Edad Media (1334-1350). Incluso, propuso algo similar a lo aquí relatado sobre el virus SARSCov-2, pero en aquella oportunidad en relación con la gripa española (1917-1919), posiblemente originada, nada más y nada menos,

\footnotetext{
${ }^{2}$ Quien se presenta en su blog como "The Cosmobiologist": <https://cosmobiota.com>.

${ }^{3}$ Para el siglo xviI, con las aportaciones de Kepler, Copérnico, Galileo, Brahe, entre otros, difundidas en la Nueva España gracias al mercedario Diego Rodríguez, el cielo se dividía, a grandes rasgos, en el geocentrismo ptolemaico y el heliocentrismo copernicano. Tycho Brahe conjugó ambas nociones y esta postura fue la aceptada por la Iglesia, pues la tierra seguía en el centro de la galaxia y no contraponía a la literatura cristiana (Priani Saisó \& Aparicio Sedano, 2016, pp. 59-80).
} 
que por el cometa Halley, que resplandeció en los cielos cuatro años antes de la Primera Guerra Mundial. Sin embargo, el científico no abunda en este candidato y, en su lugar, propone como verdadero responsable de aquella enfermedad al cometa Encke, que estuvo muy cerca de la tierra en 1908 y en 1914, y estuvo en perihelio en 1918. Según Wickramasinghe, en cada aproximación el cometa Encke perdía hielo, roca y polvo, que se esparcieron a través de la atmósfera de la tierra. De hecho, considera la evidencia que sugiere que un trozo de este cometa fue el que pudo haber explotado sobre la tierra en Tunguska, Rusia, en 1908, destruyendo más de $2000 \mathrm{~km}^{2}$ de bosque. Todo esto $-\mathrm{y}$ más- asentado en su artículo académico "Comets and Contagion: Evolution, Plague, and Diseases from Space" (Wickramasinghe \& Rhawn, 2010, pp. 1750-1753).

No obstante, a pesar del alto grado de documentación mostrado sobre la tradición cometaria del orbe occidental ${ }^{4}$ y el miedo que históricamente ha provocado en los humanos, el científico no alude a ciertas localidades, como el territorio novohispano, donde también se desarrolló, de manera célebre, esta cuestión. Así pues, para ejemplificar esta tradición dentro del género literario del tratado astronómico-astrológico he elegido un texto que surge como una de varias respuestas ante el Manifiesto philosóphico contra los cometas, despojados del imperio que tenían sobre los tímidos, que escribiera don Carlos de Sigüenza y Góngora, y que culminará con la escritura del texto científico más célebre durante los trecientos años de los virreinatos americanos: Libra astronómica y filosófica, texto con el que, como ya se ha demostrado (Trabulse, 2010), el erudito eligió por contrincante al jesuita Eusebio Kino para debatir sobre los come-

${ }^{4}$ Debe señalarse que el artículo no se limita exclusivamente a señalar esta tradición para el orbe occidental: "Ancient Chinese astronomers chronicled numerous episodes where the apparition of comets preceded plague and disaster. Meticulous observations were compiled in $300 \mathrm{BC}$ in a series of books known as the 'Mawangdui Silk'. It details 29 different cometary forms and the various disasters associated with them, dating as far back as 1500 B. C. [...]. If there is any truth to these claims, then we should also ask if comets, or other stellar objects, have caused not just death an disease, but the eradication of entire species leading to extinction" (Wickramasinghe \& Rhawn, 2010, pp. 1750-1753). 
tas y el supuesto mal que podían provocar. Dentro de esta disputa, bien conocida, la historiografía literaria no ha pasado por alto la relevancia de otras posturas en contra de Sigüenza y Góngora, entre éstas la que sostuvo el médico y catedrático de cirugía y anatomía en la Real Universidad de México, en 1678 y 1682, Joseph de Escobar Salmerón y Castro, ${ }^{5}$ quien defendió, con su tratado, la injerencia de los cometas en las personas y su responsabilidad como causante de la pestilencia, entre otros tantos males. Sin embargo, quizá no se ha atendido como mereciera la aportación a la literatura médica de esta obra, enclaustrando sus alcances, exclusivamente, como una refutatio escolástica y medievalizante en comparación a la moderna postura y fuentes modernas manejadas por su contrincante. El propósito final al que pretendo llegar con estas páginas será establecer que desde la tradición cometaria, si bien la teoría de Wickramasinghe ha recibido el calificativo de "disparatada" en la actualidad, existen ciertas posturas desde la medicina novohispana de finales del siglo XVII que, con sus matices, demuestran que, al parecer, ciertas comunidades de personas instruidas -representadas por Sigüenza y Góngora- también leyeron a Joseph de Escobar Salmerón y Castro con el mismo calificativo, aunque, sin duda, otras las aceptaron sin más. ${ }^{6}$ Por lo tanto, diversos factores, relacionados con la salud y la búsqueda de un origen para una pandemia, perviven desde la sociedad novohispana hasta el México de hoy en día. Finalmente, la elección del texto responde también a una necesidad personal: entender, desde mi realidad vivida en México, que hay una conexión entre los relatos detonados por pandemias pasadas, vividas por distintas comunidades que integraron la sociedad novohispana, y los que se viven, desde diversas circunstancias y comunidades, en la actual pandemia.

${ }^{5}$ Véase algunos aspectos biográficos de este médico criollo, descendiente de conquistadores, en Tena Villeda (2003).

${ }^{6}$ Tal y como hoy en día existen comunidades de nuestras sociedades que no creen en las vacunas más que como fuente millonaria de ingresos para las farmacéuticas. 


\section{UNA DEMOSTRACIÓN CON RESENTIMIENTO}

Que los cometas auguraran desgracias para las personas no era una cuestión que se materializaba, exclusivamente, en los libros escritos por médicos, cirujanos latinistas o astrónomos-astrólogos. Esta creencia también se manifestaba en libros religiosos, sumamente populares desde finales de la Edad Media hasta el siglo XviII, libros que seguían y daban sentido al calendario litúrgico cristiano -y con ello, al tiempo vivido en la esfera de lo sagrado y lo profano-, como el Flos sanctorum (Anónimo, 2018), mismo que llegó -y se le dio un uso bien difundido- a la Nueva España, formando parte de los bienes de indígenas caciques, desde finales del siglo XVI. En uno de lo primeros ejemplares impresos que aún conservamos de este género literario, aparece la siguiente declaración:

E las estrellas se llaman assus: que son vapores resplandecientes que tienen semejança de estrellas. E según la opinión del pueblo se dizen caer las estrellas del cielo quando aquellos como vapores que parescen estrellas descienden. E así la Scriptura se conforma a la común manera de fablar. Ca entonce especialmente se fará la tal inpresión: por quanto la calidad del fuego abundará. E esto fará nuestro Señor por espantar los peccadores. O las estrellas sedizen caer: porque echarán fuera como colas e cabellos de fuego o por muchos eclesiásticos que parecían estrellas caerán a baxo: o porque arredrarán su lumbre porque no sean vistos (Leyenda de los santos, Impreso por Juan de Burgos, 1497, f. IIIc).

Evidentemente, esta glosa textual refiere al Apocalipsis (6, 12-13) y una de sus diez señales. El pasaje condensa el temor que en el pueblo llano causaban las apariciones celestes -cometas, estrellas fugaces, etc. -, temor que los predicadores se encargaban de acentuar, tal y como se prueba en el pasaje citado, perteneciente a la lectura doctrinal del Adviento -sermón que se pronunciaba al final del otoño, hacia el último mes del año-, en donde el mensaje cardinal a ser aprendido es sobre el día del Juicio Final y la llegada, nada más y nada menos, del Anticristo.

Estas nociones medievalizantes aún estarán presentes -como tantos otros aspectos e ideas bajomedievales heredados al Nuevo 
Mundo- en la barroca sociedad novohispana, tanto así que don Carlos de Sigüenza y Góngora escribirá para intentar romper con estas creencias. Gauger (2015) ha escrito uno de los trabajos recientes más ambiciosos sobre la polémica cometaria que involucró al amigo de sor Juana. En este trabajo, nos explica que, en noviembre de 1680, Gottfried Kirch observó en Baviera un cometa, que ha recibido distintos nombres: conocido como cometa C/1680 V1, se le ha nombrado cometa Kirch, Newton y Gran Cometa de 1680 (p. 12). También recibió el nombre de cometa Hyppeo, siguiendo las nueve diferencias propuestas por Plinio: "que representándolo la cauda como crines de la cola de un caballo bien peynada, según se representó la nuestra, se llama Hyppeo, como doctamente le denominó D. Carlos de Sigüenza y Góngora" (De Escobar Salmerón y Castro, 1681, f. 17r). El propio Wickramasinghe, en su aludido artículo académico, refiere el avistamiento de este cometa desde Nueva Inglaterra, mismo que generó un virulento sermón, titulado "Alarma del cielo para el Mundo", en donde su autor, el clérigo puritano Increase Mather (1639-1723), señaló que el cometa era signo de la furia de Dios y advertencia de enfermedad, peste y desastre (Wickramasinghe \& Rhawn, 2010, p. 1764). ${ }^{7}$

El avistamiento hizo que Sigüenza y Góngora escribiese su $\mathrm{Ma}$ nifiesto philosóphico contra los cometas, despojados del imperio que tenían sobre los tímidos y lo imprimiese a inicios de $1681 .{ }^{8}$ Se trata de un trabajo de divulgación dedicado a un personaje femenino: la virreina María Luisa Manrique. Como su título lo indica, el mensaje intentaba ser tranquilizador, despojando a los cometas de toda influencia maléfica. Pese a la intención, este escrito generó tres respuestas, que objetaban lo ahí referido, anclándose en una tesis opuesta. Sin lugar a dudas, la más célebre de éstas fue Exposición astronómica de el cometa (México: Imprenta de Francisco Rodríguez Lupercio, 1681), del jesuita tirolés Eusebio Francisco Kino, contra quien irá frontalmente Sigüenza y Góngora en su Libra astronómica y filosófica, pues

${ }^{7}$ Las traducciones de este artículo son mías.

${ }^{8}$ No se conserva el ejemplar original, pero fue copiado íntegramente en Libra astronómica y filosófica (Gauger, 2015, p. 13). 
no sólo en aquel trabajo el jesuita, formado en la Universidad de Ingolstadt, tuvo la osadía de dedicarlo al virrey, Tomás Antonio de la Cerda y Aragón, conde de Paredes y marqués de la Laguna de Camero Viejo, sino que, además, desde esta postura, que aludía al máximo poder virreinal, y desde la autoridad jesuita puso en jaque las credenciales académicas del novohispano como poseedor, desde 1672, de la cátedra de matemáticas y astrología en la Real Universidad de México. Pero antes de esta explosión erudita, al Manifiesto philosóphico contra los cometas, despojados del imperio que tenían sobre los tímidos de Sigüenza y Góngora también lo encararon los textos de Martín de la Torre y, por su puesto, Escobar Salmerón y Castro.

De las tres refutaciones, la única que provino de mano de un médico de formación fue la de este último. Su texto de 1681, Discurso cometológico y relación del nuevo cometa, tenía una historia previa contra Carlos de Sigüenza y Góngora. En julio de 1672, ambos se presentaron como aspirantes al concurso de oposición para la cátedra de matemáticas y astrología en la universidad. Joseph de Escobar Salmerón y Castro resulto ser el perdedor. Una segunda y humillante derrota del médico tiene lugar en Libra astronómica y filosófica. Ahí su autor declara que, mientras sí consideró dar respuesta al Manifiesto cristiano en favor de los cometas mantenidos en su natural significación, de Martín de la Torre -“caballero flamenco"-,, por el contrario, a su antiguo rival en la búsqueda de un sueldo estable en la universidad, le clavó estas palabras:

Fue el segundo [en responder contra el Manifiesto philosóphico contra los cometas, despojados del imperio que tenían sobre los tímidos de Sigüenza] el doctor Joseph de Escobar Salmerón y Castro, médico y catedrático de anatomía y cirugía en esta Real Universidad, imprimiendo un Discurso cometológico y relación del nuevo cometa, etc., a quien jamás pienso responder, por no ser digno de ello su extraordinario escrito y la espantosa proposición de haberse formado este cometa de

\footnotetext{
${ }^{9}$ Según Sigüenza y Góngora, la respuesta tuvo lugar en su escrito titulado: Belerofonte matemático contra la quimera astrólogica.
} 
lo exhalable de cuerpos difuntos y el sudor humano (Sigüenza \& Góngora, 1984, p. 19).

A pesar de esta claridad, no ha faltado quien asegure que sí le dio respuesta, aunque sea de manera indirecta (Cotarelo Lira, 2015). Sin lugar a dudas, Sigüenza veía en las palabras del médico una variante sobrecargada en la parte arcaizante de una tradición que él buscaba innovar dentro de la ortodoxia y normatividad institucional de su tiempo, que compartía con sus contrincantes. El sesgo católico contrarreformista es el rasgo más contundente de esta ortodoxia y normatividad, en una prosa de alto contenido de documentación y tecnificación, donde el concepto de la auctoritas lo es todo. Dentro de los tres siglos de la literatura médica novohispana, ya se ha atendido y revisado esta característica por distintas materialidades de la cultura escrita médica. Así pues, Escobar Salmerón y Castro debe este elemento a una tradición, que, en su caso particular, encuadra sus ideas bajo el amparo "del Gloriosíssimo Patriarcha san Joseph, Esposo de Nuestra Señora y amantíssimo Patrón de Esta Nueva España" (De Escobar Salmerón y Castro, 1681, portada, Figura 1). La fuerte devoción por san José desde finales del siglo XVII -quien desde el Primer Concilio Provincial Mexicano (1555) ostentaba este patronazgo, con fiesta en cada 19 de marzo- ${ }^{10}$ llevará al Santo Oficio a prohibirla unos setenta años después, durante la segunda mitad del siglo XviII.

10 “Tít. III, \ II.- Señor san José, patrono de esta provincia. Siendo en verdad extraordinaria la devoción con que se honra, obsequia y reverencia en esta provincia al castísimo patriarca señor san José, esposo de María santísima, por cuyos méritos e intercesión puede creerse piadosamente que la Nueva España ha sido favorecida de Dios con particulares beneficios, lo proclamó el concilio provincial celebrado en el año del Señor 1555, como patrono general de este arzobispado y provincia, y mandó que se guardase el día en que se solemniza su festividad. Por tanto, este concilio, renovando y confirmando aquella proclamación, decreta que se celebre con octava semejante festividad en esta provincia. Pero si la octava cayere en semana santa, celébrese hasta el miércoles inclusive de la misma semana. También se manda celebrar con octava la festividad de Santiago apóstol, por ser patrono principal y general de España. Cuando se rezan los sufragios de santos en vísperas y maitines, debe preceder su conmemoración, porque es patrono más antiguo, a la conmemoración del señor san José. En cuanto al día 30 de diciembre, en que se solemniza la traslación del apóstol Santiago, récese el oficio propio de ella" (Martínez López Cano, 2004, p. 91). 
La devoción del médico tiene su fundamento en que, ante males tan nefastos como los cometas, se requería de la fuerza de un varón para afrontarlas, virilidad que, con un juego de retórica barroca, toca y ensalza también hasta el mismísimo rey:

De tan seguro Patrón, el empeño de las amenaças, y temores, que se puede inducir este Cometa presente, como temeroso aborto de las errantes lumbreras; por cuyo Patrocinio assimesmo se ofrece verdadera confianza para toda su Corona Española: que así como el Sol en la vuelta entera, que da al Orbe en 24 horas; una hora no dexa de alumbrar, fomentar, y vivificar tierra de su gran Monarcha Rey y Señor D. Carlos Segundo (De Escobar Salmerón y Castro, 1681, f. Iv).

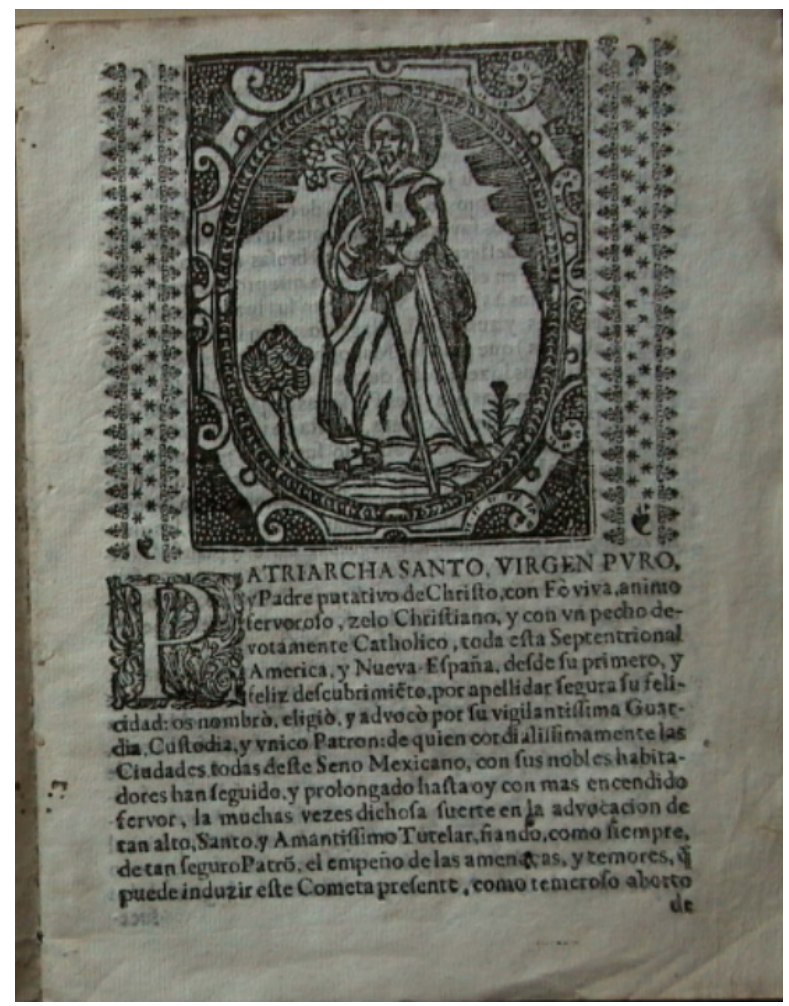

Figura 1. San José en Discurso cometológico, y relación del nuevo cometa (De Escobar Salmerón y Castro, 1681, México: Viuda de Bernardo de Calderón). 
Quizá también esta decisión de ignorar a su colega, catedrático de anatomía y cirugía, se debía, precisamente, a esta formación suya, aunque la relación es muy próxima entre estas dos actividades. ${ }^{11}$ Por ejemplo, los aspectos astrológicos son fundamentales para aplicar uno de los tratamientos más notorios de la medicina arcaica: la sangría. Pese a ello, lo cierto es que el planteamiento del discurso es opuesto entre estos colegas de la Real Universidad de México. Evidentemente, Sigüenza y Góngora valida su postura en la tradición astronómica-astrológica y su abstracción matemática, mientras que, como médico, Joseph de Escobar está muy preocupado por mostrar la delicada armonía entre el microcosmos -el interior del hombre- y el macrocosmos -lo que le rodea-, desde los postulados de la teoría humoral, que sostenía la medicina hipocrática galenista arabizada de su tiempo. El extremo de su escolasticismo medievalizante lo demuestra en el mismo folio donde alude esta teoría, sin dejar de ofrecer una correspondencia geométrica con el número siete y el cuatro, enmarcada en una interpretación simbólica de la naturaleza:

Y así como de lo alto de los orbes superiores, vengan los influjos a esta máquina inferior de los siete Planetas, que tan sensiblemente experimentamos; así mesmo del celebro como de su primer origen bajan (según más cierta opinión) los siete pares de nervios, a todo el cuerpo humano, para diversas acciones [...]. Siete asimismo son las edades del hombre, y si quatro los elementos del mundo, quatro los humores del hombre; y si en este los espíritus todo lo penetran, registran y visitan: en el ayre en el mundo por su sutileza, todo lo anda, y escudriña; es un espacioso campo donde se aparecen diversidad de Metheoros, como nubes, aguas, yelos, rocios, relámpagos, truenos, rayos, dragones, chasmas, globos, y oros diversos Metheoros, cuya materia es el fuego; y según probable opinión estrellas

${ }^{11}$ Señalados por el propio autor en el prólogo: "El segundo motivo, que me detenía, era el huir la distracción de mi precissa, y legítima ocupación de Medicina, cuya continua vigilancia, se queja aún del más breve rato, que se le divierte: mas como con tanta estrechez, se den estas dos ciencias las manos; no fue dar de mano a la Medicina, el usurparle en el curso de sus tiempos, algún tiempo, para este Discurso" (De Escobar Salmerón y Castro, 1681, f. Ir). 
volantes, y Cometas; es en fin el ayre una mera recepción del día y de la noche [...], en fin es el ayre, el primero que experimenta las calidades de los astros, que producen en estos inferiores, pues en el se experimentan las variedades de los tiempos, de frío, y calor; en él se sustentan las Aves, con él respira todo viviente, con él vive si puro le goza, con él muere si inficionado de qualidad contraria le inspira (De Escobar Salmerón y Castro, 1681, f. 3r).

Por curioso que parezca, nuestro astrofísico del siglo xxI parece retomar algo de esta tradición asentada por Escobar Salmerón y Castro. Por su puesto, Wickramasinghe no habla del aire y su importancia para el macro y microcosmos, pero sí comenta también de las aves, sugiriendo que ciertas enfermedades pandémicas vinieron del cielo. Él habla de que los rayos uv y las fluctuaciones en la actividad solar son factores a considerar cuando se busca el origen de microbios en la atmósfera superior llegados desde el espacio. Así pues, los microbios que sufren daño causado por los rayos UV o mutaciones por el incremento en la actividad solar pueden insertar estos genes dañados en otras bacterias e infectar a animales y plantas en la tierra. Por ejemplo, de la gripa española de 1918 señala que fue causada por una combinación de nuevos con viejos genes virales, creando un mortal híbrido que mató cerca de 100 millones de personas. Las primeras en infectarse fueron las aves, sugiriendo así el origen de una enfermedad venida del cielo hacia la tierra (Wickramasinghe \& Rhawn, 2010, p. 1759).

Por otra parte, el pasaje citado evidencia que nuestro médico, Joseph de Escobar Salmerón, se recargó en la base más arcaica para defender su tesis cometaria. Y es que, si se revisa la tradición de la literaria médica que le precedió en la Nueva España, nadie se muestra tan particularmente medievalizante en materia de cometas como él. Fray Agustín Farfán, célebre médico agustino de la segunda mitad del siglo XVI, gracias a su formación universitaria -en Sevilla y Alcalá de Henares- sabe del influjo del macrocosmos en las apostemas, bajo la autoridad de Aristóteles. Sin embargo, apenas si da dos breves menciones de ello, primero en su Tratado breve 
de anatomía y cirugía (1579) ${ }^{12}$ y luego en su Tratado breve de medicina (1592 y 1610). ${ }^{13}$ Juan de Barrios, quien publicará en 1607 su Verdadera medicina, cirugía y astrología, en el apartado de astrología se decantará, precisamente, por no aceptar abiertamente supersticiones relacionadas con los cometas. ${ }^{14}$ Con ello, deja ver una postura sesgada a la supuesta influencia de los astros. Sorprende que setenta y cuatro años después, Joseph de Escobar, como médico de formación universitaria, se mostró lejos de abundar en lo propuesto por De Barrios o mostrar la mesura cauta de Farfán. Por el contrario, se decantó por un alto nivel de oposición ante la modernidad de ideas de su tiempo, bien representadas por los escritos de Carlos de Sigüenza y Góngora. Su rencor y constante frustración contra el amigo de sor Juana ya ha sido documentado (Tena Villeda, 2003, p. 12). Dentro de este mismo tenor, ¿acaso su texto se debe sólo a un encono personal? ¿Una respuesta que sólo buscaba manifestar lo contrario a lo expuesto por quien le ganara una plaza en la universidad años atrás? Por supuesto, grandes revolucionarios del pensamiento astronómico, como Copérnico, Brahe, Kepler, etc., no se desdecían de la astrología como predicción del futuro (Vernet, 2000, pp. 16-31), pues era una parte inherente a su arte. Ni siquiera el propio Carlos de Sigüenza y Góngora se desprende de

12 "Como lo dize Aristóteles en el quarto [libro] de los Metheoros, que en todo lo que se podrece, es necessario hallarse calor extraño, y por esta razón todos los Tumores o Apostemaas fríos peden ser calietes por putrefactio" (f. $34 \mathrm{v}$ ).

${ }^{13} \mathrm{El}$ zaratán comienza como una lenteja y casi no tiene dolor. Va creciendo, poco a poco, y algunas veces "crece o disminuye con las lunas" (f. 305a).

14 “¿No se ven cometas, no significan muertes de Reyes, pestes, guerras? Digo que sí: pero quién ha dicho, qué Reyes, y en qué Reynos: y quántos y según los antiguos escriben el año de 1558. Se vo ua cometa en el principio de Agosto, duró hasta fin de Setiembre, este año se murió el Emperador Carlos, María Rey de Yngalaterra. Y el Rey Enrico Rey de Francia. Estas muertes dudo yo vista la cometa, ¿quién las anunció, quién avía de ser, y quántos, y adónde? Mas bien saben vs. ms. que quando estudiábamos Artes en Alcalá de Henares, por el mes de Enero, se vio una cometa; aquel año succedio lo de Portugal; ¿quién lo predixo? Lo que avía de suceder con estar enfrente del patio de Cordovilla, en el hospital de los estudiantes, el Do. Segura, hombre docto en sancta Theología, y en esta arte, me acuerdo, que muchas noches nos yvamos a su casa, y le preguntávamos que nos dixesse; que de nota lo que a nosotros nos parescía espanto. Sólo le oy decir, que lo que sucedería no sería en España” (f. 44v). 
esta conceptualización. Sólo que Trabulse (2010) se ha empeñado en limpiar todo sesgo arcaizante del erudito novohispano, pero, justamente, la tajante separación entre avanzada científica astronómica y el arcaísmo astrológico no es viable para la literatura científica de la época. Afortunadamente, hay ya destacados trabajos de investigación que han influido en tesis recientes (Welke Laborde, 2019), que ya no postulan por esta equivocada escisión. Así pues, en este sentido, Joseph de Escobar se recarga sólo en una de las dos bases de una tradición astronómica-astrológica, bien vigente en su tiempo -para prueba, los textos de Kino y De la Torre-, con sus respectivos matices.

Uno de estos matices es sobre la naturaleza del cometa observado. El médico nos dice que cualquier generación dentro del orden natural precisa de cuatro causas: "Efficiente, Material, Formal y Final." En lo que respecta a la primera, son el sol y los planetas, que con sus rayos y luces elevan vapores y exhalaciones de todo lo que hay de evaporable en la tierra. Esto se ve con más eficacia si en el cielo hay "Conjunciones Magnas o Eclipses" (f. 7v), hecho que se comprueba desde el punto de vista médico, pues en esos días de fenómenos naturales hay efectos "en los mismos cuerpos humanos, acrecentando dolores en Gálicos, ansias e inquietudes en los Febricantes" (f. 7v). Y esta teoría, comprobada en astrología, nos dice el doctor que fue "observada por mí, en este Cometa" (f. 7v).

La causa material la provoca todo lo evaporable y "exhalable" en la tierra -como plantas, agua, tierra, cuerpos vivientes y hasta cuerpos de los muertos sepultados-, pero principalmente el hombre:

con sus espíritus, y humores; $\mathrm{y}$ aunque al primer visto paresca dificultoso: desata la duda, el ver, que la lluvia, tiene por su materia, de que se forma, al mismo sudor del hombre, pues el Sol le arrebata para sí subiéndole a la región primera, en donde recibiendo la forma de agua, cae a la tierra en tanta abundancia; y que arrebate en sí este sudor el Sol, se confirma aun en los mismos caminantes, en quienes en las partes que toca el Sol, no se ve el sudor, porque lo arrebata para lo alto con su calor; y las partes que van abrigadas, y no las toca sudan en abundancia, como se ve en lo alto de la frente que ocupa el sombrero (De Escobar Salmerón y Castro, 1681, f. 7v). 
La autoridad que respalda esta declaración es el mismo Hipócrates, es decir, es el hombre con sus espíritus y humores la causa material de los cometas. Además, Joseph de Escobar afirma que esta causa la ha experimentado él y "mis compañeros, y Doctos Médicos, en esta populosa República” (f. 8r). Esta comprobación aludida por el autor recae en una epidemia observada desde 1678: "granos, póstulas, o ronchas, tan molestas, y tan sin falta de veneno, y malignidad, que sin ceder a medicamentos de qualidades manifiestas, no han perdonado, no por la piedad al viejo, ni al niño por su inocencia" (f. 8r). Además, reporta que el año de 1680 hubo una epidemia de fiebres tercianas. Afirma que la causa de todos estos males fue "la Materia del Cometa, que como se iba congregando, y uniendo para llegar a su incendio era necesario el que los Astros, que causarían esta atracción de ella, fuessen exalando, y como chupando de los mismo cuerpos humanos todo aquello que era exalable, y vaporable" (f. 8r). A pesar de estas declaraciones -que dan fe de la experiencia de lo escrito, no sólo por parte del autor, sino que, supuestamente, también por parte de otros colegas médicos, a quienes, por desgracia para nosotros, no cita por su nombre-, lo cierto es que no armonizan con la tradición de la literatura médica precedente. Y es que durante el siglo XVII parece que la peste nunca dejó de formar parte de la sociedad novohispana o al menos esa es la intención que trata de dejar en claro Juan de Barrios. En su aludido libro, declara que en la Nueva España no había un solo mes del año en donde no se sufrieran fiebres tabardetes, una fiebre que ha sido asociada con la peste. En su libro de 1592 -reimpreso en 1610-, fray Agustín Farfán incluía un capítulo titulado "Breve tratado de todas las calenturas y de las curas de ellas", apartado que alude, precisamente, a uno de los síntomas determinantes en tiempos de peste. En otras palabras, no se sostiene la afirmación de Joseph de Escobar sobre que el cometa de 1680 provocó síntomas pestilenciales en la sociedad novohispana de su tiempo. De la misma manera que no se sostiene la veracidad de la teoría del astrofísico Chandra Wickramasinghe, pese a sus esfuerzos. A pesar de sus tesis científicas propias del siglo xxI y, quizá, precisamente porque no ha logrado probar su teoría, parece que se recarga mucho en 
una tradición literaria sobre la disputa cometaria. Curiosamente, el recargamiento tiene algo de parentesco -algo de familiar remoto- en la exposición del médico novohispano, Escobar Salmerón y Castro, y sus ganas de justificar un mal pestilencial de los últimos veinte años del siglo XVII.

En el fondo, las dos propuestas aluden a un relato universal: las múltiples incertidumbres que en el ser humano causa la inmensidad del cielo y sus cuerpos celestes. Durante siglos, se ha creído que algo fuera del orden conocido puede romper la frágil comodidad en la que insertamos nuestra existencia. Por ejemplo, Vernet (2015, pp. 24 y ss) recuerda que astrólogos indios pronosticaron el fin del mundo en 1962, debido a la conjunción y alineación planetaria del Sol, la Luna, la Tierra, Mercurio, Júpiter y Saturno. Se busca en el espacio exterior el fin de los tiempos, pero también el origen de la vida de males terrestres, como una enfermedad pandémica. Wickramasinghe y Escobar Salmerón y Castro comparten el mismo gesto: ambos miraron al cielo -cada uno desde sus respectivos tiempos, circunstancias y realidades- para encontrar una respuesta, que no está despojada de una tradición literaria en torno a los cometas.

\section{CONSIDERACIONES FINALES}

Los astros fueron consultados desde las primeras pestilencias, tras la consolidación de la conquista y asentamiento de las primeras instituciones en la Nueva España. Sin lugar a dudas, dentro de la tradición de la literatura médica que vio por esta cuestión, la obra de Joseph de Escobar Salmerón y Castro es de las más interesantes. Lo es por la ciencia de su tiempo, que recoge, y por el relato que se construye con su teoría. La desestimación de la misma, desde su origen -y cuya representación más célebre recae en la opinión de su contrincante, Carlos de Sigüenza y Góngora-, es un factor que comparte con la teoría de Wickramasinghe para el origen de la actual pandemia: SARS-COV-2.

En la ciencia, los hechos no se argumentan, se comprueban. Precisamente en esta argumentación, sostenida en una tradición literaria sobre la disputa cometaria, es que tanto el médico criollo 
del siglo XVII como el astrofísico cingalés del XXI comparten cierta equidad en sus teorías. El relato, la narración, la historia que ambas teorías construyen es sumamente atractiva, si bien no para la veracidad científica, sí que lo es para la imaginación. Por supuesto, no hay una correlatividad directa entre uno y otro texto. Wickramasinghe es un científico de nuestro tiempo -en donde fue posible lograr una vacuna contra la COVID-19 en cuestión de meses- y Escobar Salmerón ejecutaba su ciencia, la medicina, en un mundo barroco, donde aún no se había marcado claramente la frontera entre literatura y discurso científico, tal y como los concebimos hoy en día. En efecto, la sociedad barroca decía consumir el polvo de momia para restituir la carne gangrenada del ser humano; el cuerno de unicornio para la cura de la fiebre tabardete, el mal de cámara, la peste y el envenenamiento; etc. Estos eran sólo dos de los fármacos del mundo médico de Joseph de Escobar Salmerón y Castro, fármacos que hoy en día sólo existen en la literatura médica, mas no en la real búsqueda de la salud. Evidentemente, en aquel mundo barroco cabía también la creencia sobre un aire novohispano ya infecto por culpa de los eclipses de un año anterior al cometa de 1680 (f. $8 \mathrm{v})^{15}$ y advertir que un cometa podía producir efectos propios y otros, comunes:

como en México el afecto catarroso. Morir, o no morir muchos de este achaque, es acidente común; porque aunque mueran muchos, o pocos dél: siempre es catarro; pero el morbo epidemial tiene por accidente proprio el que mueran muchos, porque le es muy proprio a este achaque pestífero el darle a muchos, y a estos matarlos; de suerte, que si pocos murieran dejara de ser morbo pestilente, o epidemia lo qual milita con la misma razón en los Cometas (De Escobar Salmerón y Castro, 1681, f. 18r-18v).

${ }^{15}$ Además de que creer "que quando en algún Eclipse tuviere Marte prerrogativa, y fuere señor de aquel año, se puede esperar producción de Cometa; y más firme, si Marte estuviere en Signo ígneo, como entonces lo estuvo, que fue el Signo de León" (De Escobar Salmerón y Castro, 1681, f. 14v). 
Y así como lo expuesto con el catarro, un cometa dejaría de ser cometa si no anunciara "pestes y carestías" (f. 18v), por no hablar de las hambrunas, muertes de sujetos principales y terremotos. Particularmente, el cometa Hyppeo provocaría en "México" epidemia "de ebullición de sangre, y putrefacción de ella, con mucha malignidad, y flujos de humores coléricos a las partes pudendas y muchas viruelas" (f. 22v).

Por su parte, Wickramasinghe nos aclara quién es el responsable de las diversas pestilencias vividas en la historia occidental: Yersinia pestis, un bacilo Gram negativo anaerobio facultativo y patógeno primario, que carga, según él, la responsabilidad de la peste justinianea -siglos VI-VIII-, la peste negra - "siglo siglos XIV-XIX" (sic) - y la peste moderna -siglo xxi. El misterio con Yersinia pestis es que resiste la congelación. El mayor ambiente anaeróbico, congelado, se localiza en el espacio exterior, "Por lo tanto, ¿estos microbios podrían haberse originado en el espacio exterior?" Y más adelante, declara: "Hasta ahora, no hay razón para pensar que la materia orgánica encontrada en cometas no fuera producida por organismos biológicos. Los microbios pueden prosperar o yacer latentes en el corazón de los cometas" (Wickramasinghe \& Rhawn, 2010, pp. 1756 y ss).

Dos teorías, una del siglo XVII y otra del siglo xxi, sustentadas en la tradición literaria sobre la disputa cometaria. Tanto en una como en otra los relatos que orbitaron alrededor del temor de una pandemia se hacen presentes. Joseph de Escobar de Salmerón lo tenía claro: el pronóstico del cometa Hyppeo no sólo afectaría la salud; también los frutos de la tierra; y provocaría terremotos. El miedo que debieron sentir las comunidades no instruidas -e incluso las que sí lo eran- ante estos terribles pronósticos y los relatos que se generaron debido a un comportamiento guiado por el miedo -muerte de reyes; nacimiento de monstruosidades en bestias y humanos; frutos con pelo y formas nunca vistas en los cereales, etc.- lo entendemos mucho mejor hoy en día. En efecto, en pleno siglo Xxi México vio nacer y/o repetir algunos de los peores relatos mundiales causados por la pandemia: la misteriosa escasez de papel higiénico en los supermercados y en comercios pequeños; la 
agresión física contra médicos y enfermeras por parte de vecinos, al pensar que ellos eran los responsables de propagar la enfermedad; el miedo a que un chip controlador fuese injertado bajo la piel, mismo que era contenido, de algún modo, en las vacunas; los mexicanos -maestros, profesores y profesionales de la educación pública- vacunados con CanSino, medicamento no reconocido, hasta el momento, por la Organización Mundial de la Salud; etc.

Como no se veía desde hace mucho, a filólogos e historiadores abocados al estudio de fuentes medievales y de la temprana modernidad se les ha requerido para que cuenten los relatos de cómo se vivieron pandemias en la antigüedad. Con estas páginas, he intentado aportar a esta causa, desde el periodo barroco novohispano al México de hoy, una localidad que juega su papel en el orden global que sigue padeciendo la actual pandemia.

\section{BIBLIOGRAFÍA}

Anónimo. (2018). Flos sanctorum con sus ethimologias: Lo maravilloso hagiográfico. (Edición de M. Cortés Guadarrama). Xalapa: Universidad Veracruzana.

Cotalero Lira, R. x. (2015). La ¿polémica? entre Carlos de Sigüenza y Góngora y Josef Escobar Salmerón y Castro sobre los sometas. (M. I. Terán, A. Ortiz, v. M. Chávez Ríos \& M. C. Fernández Montemayor, coords.). Perspectivas históricas y filosóficas del discurso novohispano (pp. 267-276). Zacatecas: Texere Editores.

De Escobar Salmerón y Castro, J. (1681). Discurso cometológico, y relación del nuevo cometa: visto en aqueste Hemispherio Mexicano, y generalmente en todo el Mundo: el Año de 1680; Y extinguido en este de 81: Observado y Regulado en este mismo Horizonte de México. México: Viuda de Bernardo de Calderón.

De Sigüenza y Góngora, C. (1984). Libra astronómica y filosófica. (Ed. de Bernabé Navarro). México: Universidad Nacional Autónoma de México. 
Exclusivo Premium. (marzo 19, 2020). El coronavirus llegó del espacio: la disparatada teoría de un famoso astrofísico. ABC Ciencia. <https://www.abc.es/ciencia/abci-disparatada-teoria-afirma-coronavirus-llego-espacio\%20202003182146_noticia.html?ref $=$ https $\% 3 \mathrm{~A} \% 2 \mathrm{~F} \% 2 \mathrm{Fwww}$.google.com $>$.

Gauger, J. M. (2015). Autoridad jesuita y saber universal. La polémica cometaria entre Carlos de Sigüenza y Góngora y Eusebio Francisco Kino. New York: Instituto de Estudios Auriseculares.

Martínez López Cano, M. Del P. (Coord.). (2004). Concilios provinciales mexicanos. Época colonial. México: Universidad Nacional Autónoma de México.

Priani Saisó, E. y Aparicio Sedano, H. R. (2016). "No quiero latines en lo que pretendo vulgar": la querella sobre los cometas entre los universitarios, médicos y astrólogos novohispanos en la segunda mitad del siglo XVII. En A. Álvarez Sánchez (Coord.), Conocimiento y cultura. Estudios Modernos en la Facultad de Filosofía y Letras (pp. 59-80). México: Universidad Nacional Autónoma de México.

Tena Villeda, R. (2003). José Salmerón de [sic] Castro, Médico y Astrónomo Novohispano. Boletín Méxicano de Historia y Filosofía de la Medicina, 6(1), 11-16. <https://www.medigraphic.com/cgi$\mathrm{bin} / \mathrm{new} /$ resumen.cgi?IDARTICULO=15994>.

Trabulse, E. (2010). La justa de los cometas. Don Carlos de Sigüenza y Góngora y la astronomía de su siglo. México: Universidad Nacional Autónoma de México.

Vernet, J. (2000). Astrología y astronomía en el Renacimiento. Barcelona: Acantilado.

Welke Laborde, s. H. (2019). Libra astronómica y filosófica: entre la ciencia y la literatura de los Siglos de Oro. [Tesis de Maestría, Universidad Veracruzana, Xalapa]. Repositorio Institucional. <https://cdigital.uv.mx/handle/1944/50419>.

Wickramasinghe, Ch. y Rhawn, J. (2010). Comets and Contagios: Evolution, Plague and Doseases from Space. Journal of Cosmology, 71750-1770. 